(2) Open Access Full Text Article

ORIGINAL RESEARCH

\title{
Mortality following acute medical admission in Denmark: a feasibility study
}

This article was published in the following Dove Press journal:

Clinical Epidemiology

18 August 2010

Number of times this article has been viewed

\author{
Morten Schmidt' \\ Sussie Antonsen' \\ Betina Hansen' \\ Jens Møller ${ }^{2}$ \\ Carsten Thordal ${ }^{2}$ \\ Henrik Toft Sørensen' \\ 'Department of Clinical Epidemiology, \\ Aarhus University Hospital, \\ Aarhus, Denmark; ${ }^{2}$ Department of \\ Endocrinology and Internal Medicine, \\ Aarhus University Hospital, Aarhus, \\ Denmark
}

Background: As the population ages, an increasing number of acute medical patients will be older and have comorbidities that may interact with their primary admission condition and worsen their prognosis.

Objectives: To examine whether 6-month mortality following acute medical admission was associated with gender, age, or comorbidity.

Methods: We used the Danish National Patient Registry, covering all Danish hospitals, to identify all acute medical admissions to Aarhus University Hospital during 2008 and comorbidities. We obtained mortality data from the Danish Civil Registration System. We computed mortality risks and hazard ratios with 95\% confidence intervals (CIs) for gender, age, and comorbidity groups.

Results: We identified 3,727 patients (53.6\% women) with a median age of 63 years for women and 60 years for men. The overall 6 -month mortality rate was $12.8 \%$. The adjusted hazard ratio was 2.77 (95\% CI, 2.11-3.64) for patients aged 65-80 years and 5.25 (95\% CI, 4.06-6.80) for patients older than 80 years, compared with patients younger than 65 years. The adjusted hazard ratio was 2.43 (95\% CI, 1.82-3.24) and 3.87 (95\% CI, 2.91-5.15) for patients with moderate and high comorbidity, respectively, compared with low comorbidity.

Conclusion: Age and comorbidity were important predictors of mortality after acute medical admission.

Keywords: cohort study, comorbidity, epidemiology, hospital admission, internal medicine, prognosis, registries

\section{Introduction}

The aging population and the increasing prevalence of chronic conditions present major public health challenges. ${ }^{1,2}$ The western population aged 65 years and older is projected to increase from approximately $15 \%$ in 2010 to $25 \%$ by $2040 .{ }^{1,3}$ The most rapid growth will occur in age groups older than 80 years. ${ }^{1}$ Approximately $45 \%$ of the general population and $88 \%$ of the population older than 65 years have at least one chronic disease. ${ }^{2}$ The vast majority of western health-care expenditures are already related to treatment of chronic conditions. ${ }^{4}$ The increasing proportion of elderly people is expected to increase the general need for hospitalization. ${ }^{2}$ Moreover, these hospitalizations will involve patients with comorbidities along with their primary admission condition. Thus, the future burden of comorbidity requiring medical attention will further increase health-care expenditures. ${ }^{1,2}$

Identifying prognostic factors for acute medical diseases is essential in the planning of health-care needs, evaluation of effectiveness of hospital care, and prevention 
of posthospital death. Previous studies of acute medical patients' prognoses have focused entirely on the index condition. ${ }^{5}$ Therefore, we conducted a feasibility study to examine the 6-month mortality following acute medical admission in Denmark and whether it was associated with gender, age, or comorbidity level. Furthermore, we aimed at describing the potential of the present study design for prognostic research on patients who were admitted acutely to internal medical departments.

\section{Methods}

\section{Setting}

We conducted this population-based cohort study in the Aarhus city area (population, 300,000) using data from Danish National Registries. The Danish National Health Service provides universal tax-supported health care, guaranteeing unfettered access to general practitioners and hospitals, and partial reimbursement for prescribed medications. Unambiguous linkage between all Danish registries is possible using the unique 10-digit central personal registry number assigned to each Danish citizen at birth and to residents upon immigration. ${ }^{6}$

\section{Patients}

The Danish National Patient Registry (DNPR) covers all Danish hospitals and contains data on the admitting departments, admission priorities, dates of admission and discharge, and all primary and secondary discharge diagnoses from nonpsychiatric hospitals since 1977 and from emergency room and outpatient clinic visits since $1995 .^{7}$ Each discharge is associated with 1 primary diagnosis and 1 or more secondary diagnoses classified according to the International Classification of Diseases, Eighth Revision (ICD-8) until the end of 1993 and, thereafter, International Classification of Diseases, Tenth Revision (ICD-10). ${ }^{7} \mathrm{We}$ were interested in identifying medical patients only, distinct from surgical or psychiatric patients. All patients admitted to a medical admission unit (MAU) in Denmark are registered with a unique department code at the time of arrival, independently of later transfers to other departments. Using the DNPR, we identified patients with a first-ever acute admission to the MAU at Aarhus University Hospital, Nørrebrogade (code: 7003.071), between January 1, 2008, and December 31, 2008. This unit provides acute medical care for half of the Aarhus city population. The residence address determines to which hospital patients are referred. Codes for admission priorities registered independently in the DNPR confirmed that all patients identified were admitted acutely (code: ATA1). We defined the primary admission condition as the index condition and the date of admission as the index date. Per protocol, we excluded patients with a pregnancy-related index condition $(n=0)$, patients younger than 18 years $(n=83)$, and patients with missing records of vital statistics (primarily non-Danish citizens; $n=23$ ). All types of medical patients are admitted to the MAU except patients with acute myocardial infarction or stroke, who are directly admitted to specialized departments. Patient admissions last until transfer to another hospital department, discharge, or in-hospital death.

\section{Mortality}

We obtained all-cause mortality from the Danish Civil Registration System. ${ }^{8}$ This registry is updated daily and contains vital statistics - including date of birth, change of address, date of emigration, and exact date of death - on the Danish population since $1968 .^{8}$

\section{Comorbidity}

We searched the DNPR for inpatient and outpatient diagnoses for patient comorbidities before the index date. ${ }^{9} \mathrm{We}$ categorized patients' comorbidity burden using Charlson comorbidity index (CCI). ${ }^{10}$ The CCI is a validated method of classifying comorbidity to predict short-term and longterm mortality taking into consideration both the number and seriousness of diseases. ${ }^{11-13}$ In the CCI, a number of conditions are assigned weights of 1, 2, 3, or 6 . The weights are allocated as follows: 1 - myocardial infarction, congestive heart failure, peripheral vascular disease, stroke, dementia, chronic pulmonary disease, connective tissue disease, ulcer disease, mild liver disease, or diabetes mellitus; 2 - hemiplegia, moderate or severe renal disease, diabetes with complications, any tumor, leukemia, or lymphoma; 3 - moderate to severe liver disease; 6 - metastatic solid tumor or AIDS. The Charlson index score is the total of the assigned weights, and thus represents a measure of the overall comorbidity burden. ${ }^{10}$ Three levels of comorbidity were defined based on Charlson index scores of 0 (low), 1-2 (moderate), and 3 or more (high). ${ }^{14}$ The ICD codes for each of the conditions included in the CCI are provided in the Appendix.

\section{Statistical analysis}

We characterized the patients according to gender, age, comorbidity, and index condition. Patients were followed from index date until the date of death, emigration, or completion of 6 months of follow-up, whichever came first. 
Using the Kaplan-Meier estimator, we plotted a 6-month overall mortality curve and calculated the cumulative 1-, 3-, and 6-month mortality risks, overall and stratified on gender, age, and comorbidity groups. The covariates eligible for inclusion in the model as potential confounders were gender, age as a continuous variable, and comorbidity level. Using the average covariate method, ${ }^{15}$ we adjusted the mortality curves for these covariates.

Using Cox proportional hazards regression model, we calculated mortality hazard ratios (HRs) with $95 \%$ confidence intervals (CIs) comparing mortality rates within gender, age, and comorbidity groups. For each group, the category with the lowest mortality rate was set as reference, ie, female gender, age 18-64 years, and low comorbidity level, respectively. To examine any interaction between covariates, we performed stratified analyses on all 3 covariates. In the overall analysis, we adjusted for the other 2 covariates. In the stratified analysis, we adjusted for the remaining covariate only, except within age strata where additional adjustment for age as a continuous variable was made to reduce residual confounding. Analyses were performed using Statistical Analysis System (SAS) version 9.2 (SAS Institute Inc, Cary, North Carolina, USA).

\section{Results}

\section{Patient characteristics}

We identified 3,727 adult patients with a first-ever acute hospital admission during 2008 to the MAU at Aarhus University Hospital, Nørrebrogade. Patient characteristics are presented in Table 1. Slightly more than half of these patients were female (53.6\%). At index date, 2,045 (54.9\%) patients were younger than 65 years, $886(23.8 \%)$ were aged between 65 and 80 years, and 796 (21.4\%) were older than 80 years. The female patients were slightly older (median age, 63 years) than the male patients (median age, 60 years). The comorbidity level was low for 1,624 (43.6\%) patients, moderate for 1,241 (33.3\%) patients, and high for $862(23.1 \%)$ patients. The frequency and proportion of index conditions according to major $I C D-10$ groups are presented in Table 2 and Figure 1. A surprisingly large proportion (17.9\%) of the admitting causes were, rather imprecisely, coded as "factors influencing health status and contact with health services" (Z00-Z99), of which $84.9 \%$ were "medical observation and evaluation for suspected diseases and conditions" (Z03). The most frequent single cause of admission to the MAU was disease of the respiratory system.

\section{Cumulative mortality}

The cumulative mortalities are presented in Table 3 and Figures 2-5. The overall unadjusted mortality was
Table I Characteristics of patients with a first-ever admission to the medical admission unit at Aarhus University Hospital, Nørrebrogade, during 2008

\begin{tabular}{|c|c|c|}
\hline & \multicolumn{2}{|c|}{ Patients } \\
\hline & $\mathbf{n}$ & $\%$ \\
\hline Overall & 3,727 & 100.0 \\
\hline \multicolumn{3}{|l|}{ Gender } \\
\hline Female & I,997 & 53.6 \\
\hline Male & $\mathrm{I}, 730$ & 46.4 \\
\hline \multicolumn{3}{|l|}{ Age group (y) } \\
\hline $18-64$ & 2,045 & 54.9 \\
\hline $65-80$ & 886 & 23.8 \\
\hline$>80$ & 796 & 21.4 \\
\hline \multicolumn{3}{|l|}{ Charlson comorbidities $^{\mathrm{a}}$} \\
\hline Myocardial infarction & 263 & 7.1 \\
\hline Congestive heart failure & 358 & 9.6 \\
\hline Peripheral vascular disease & 279 & 7.5 \\
\hline Cerebrovascular disease & 559 & 15.0 \\
\hline Dementia & 86 & 2.3 \\
\hline Chronic pulmonary disease & 661 & 17.7 \\
\hline Connective tissue disease & 195 & 5.2 \\
\hline Ulcer disease & 335 & 9.0 \\
\hline Mild liver disease & 176 & 4.7 \\
\hline Diabetes mellitus & 531 & 14.2 \\
\hline Hemiplegia & 29 & 0.8 \\
\hline Moderate to severe renal disease & 137 & 3.7 \\
\hline Diabetes with end-organ damage & 319 & 8.6 \\
\hline Any tumor & 472 & 12.7 \\
\hline Leukemia & 4 & 0.1 \\
\hline Lymphoma & 26 & 0.7 \\
\hline Moderate to severe liver disease & 59 & 1.6 \\
\hline Metastatic solid tumor & 72 & 1.9 \\
\hline AIDS & 3 & 0.1 \\
\hline \multicolumn{3}{|l|}{ Comorbidity level $^{\mathrm{b}}$} \\
\hline Low & 1,624 & 43.6 \\
\hline Moderate & $|, 24|$ & 33.3 \\
\hline High & 862 & 23.1 \\
\hline
\end{tabular}

Notes: any hospital discharge diagnosis recorded in the Danish National Patients Registry between 1977 and the index date; ${ }^{\circ}$ Three levels of comorbidity were defined based on Charlson index scores of 0 (low), I-2 (moderate), and 3 or more (high).

5.7\% after 1 month, $9.5 \%$ after 3 months, and $12.8 \%$ after 6 months (Figure 2). Men had a slightly higher adjusted mortality compared with women (Figure 3). Patients younger than 65 years had a lower 1-, 3-, and 6 -month adjusted mortality $(0.9 \%, 1.6 \%$, and $2.3 \%$, respectively) compared with those aged $65-80$ years $(6.8 \%$, $10.7 \%$, and $16.1 \%$, respectively) and with those older than 80 years $(13.2 \%, 22.3 \%$, and $28.4 \%$, respectively). Similarly, patients with a low comorbidity level had a reduced $1-, 3-$, and 6-month adjusted mortality $(1.0 \%, 1.5 \%$, and $2.1 \%$, respectively) compared with those with moderate comorbidity level $(4.2 \%, 7.2 \%$, and $10.1 \%$, respectively) and with those with high comorbidity level $(10.8 \%, 18.6 \%$, and $24.8 \%$, respectively). 
Table 2 Frequency and proportion of primary admission conditions according to major ICD-I0 groups

\begin{tabular}{|c|c|c|c|}
\hline ICD-I 0 groups & Disease categories & $\mathbf{n}$ & $\%$ \\
\hline A00-B99 & Certain infectious and parasitic diseases & 126 & 3.4 \\
\hline C00-D48 & Neoplasms & 19 & 0.5 \\
\hline D50-D89 & $\begin{array}{l}\text { Diseases of the blood and blood-forming organs and certain disorders involving } \\
\text { the immune mechanism }\end{array}$ & 51 & 1.4 \\
\hline E00-E90 & Endocrine, nutritional, and metabolic diseases & 299 & 8.0 \\
\hline F00-F99 & Mental and behavioral disorders & 265 & 7.1 \\
\hline G00-G99 & Diseases of the nervous system & 80 & 2.1 \\
\hline $\mathrm{H} 00-\mathrm{H} 59$ & Diseases of the eye and adnexa & 3 & 0.1 \\
\hline $\mathrm{H} 60-\mathrm{H} 95$ & Diseases of the ear and mastoid process & 5 & 0.1 \\
\hline $100-199$ & Diseases of the circulatory system & 245 & 6.6 \\
\hline J00-j99 & Diseases of the respiratory system & 575 & 15.4 \\
\hline K00-K93 & Diseases of the digestive system & 76 & 2.0 \\
\hline L00-L99 & Diseases of the skin and subcutaneous tissue & 33 & 0.9 \\
\hline M00-M99 & Diseases of the musculoskeletal system and connective tissue & 117 & 3.1 \\
\hline N00-N99 & Diseases of the genitourinary system & 114 & 3.1 \\
\hline O00-099 & Pregnancy, childbirth, and the puerperium & - & - \\
\hline P00-P96 & Certain conditions originating in the perinatal period & - & - \\
\hline Q00-Q99 & Congenital malformations, deformations, and chromosomal abnormalities & - & - \\
\hline R00-R99 & Symptoms, signs, and abnormal clinical and laboratory findings, not elsewhere classified & 522 & 14.0 \\
\hline S00-T98 & Injury, poisoning, and certain other consequences of external causes & 528 & 14.2 \\
\hline V0I-Y98 & External causes of morbidity and mortality & I & 0.0 \\
\hline Z00-Z99 & Factors influencing health status and contact with health services ${ }^{a}$ & 668 & 17.9 \\
\hline
\end{tabular}

Note: 'Among z-categories, 567 (84.9\%) were admitted as "medical observation and evaluation for suspected diseases and conditions" (Z03).

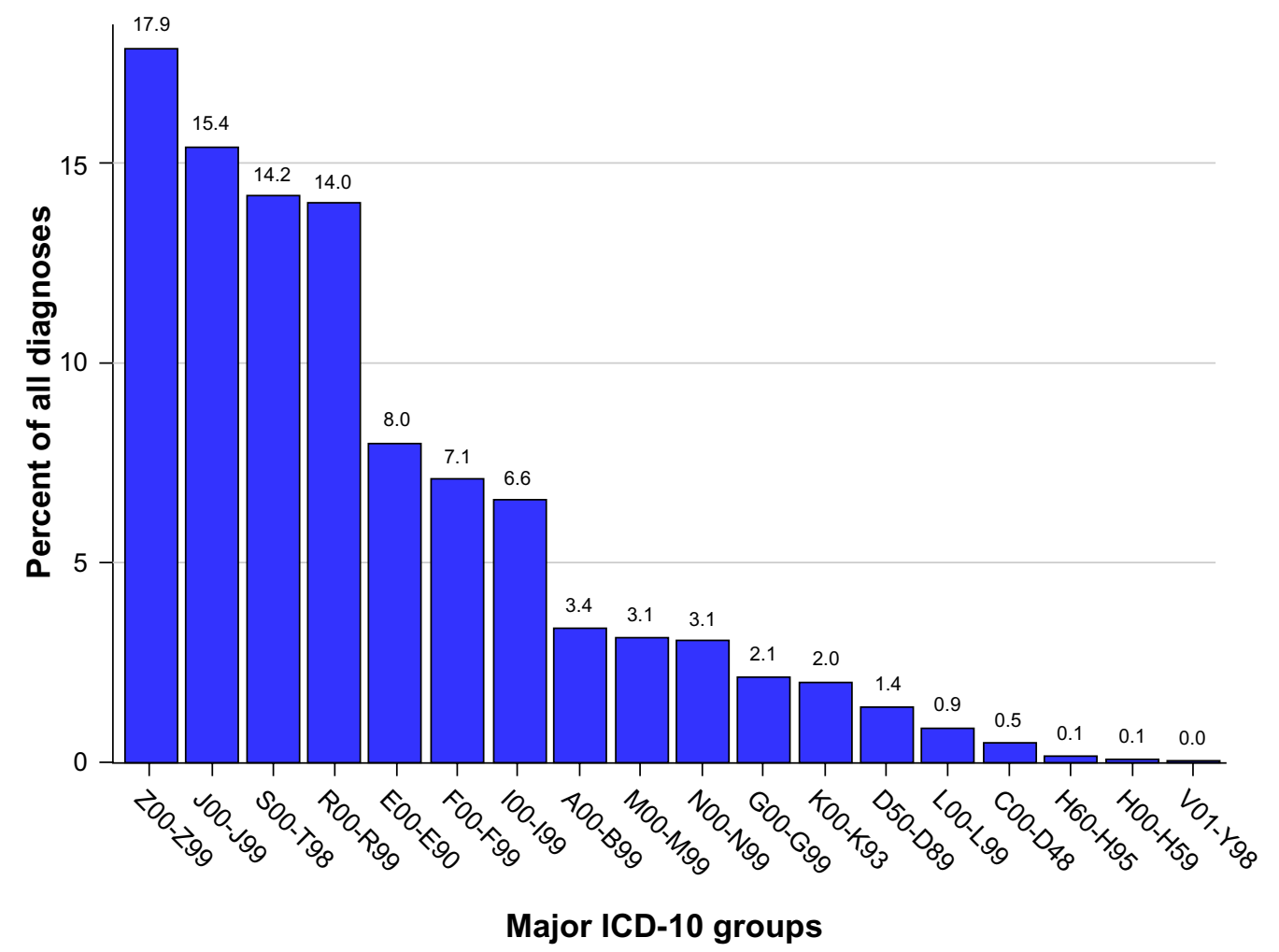

Figure I Relative frequency of primary admission conditions according to major ICD-10 groups (corresponding disease categories are shown in Table 2). 
Table 3 Cumulative mortality risk after I, 3, and 6 months, overall and according to gender, age, and comorbidity groups

\begin{tabular}{|c|c|c|c|c|c|c|}
\hline & \multicolumn{6}{|c|}{ Cumulative mortality (\%) } \\
\hline & \multicolumn{3}{|c|}{ Unadjusted } & \multicolumn{3}{|c|}{ Adjusted $^{\mathrm{a}}$} \\
\hline & I mo & $3 \mathrm{mo}$ & $6 \mathrm{mo}$ & I mo & $3 \mathrm{mo}$ & $6 \mathrm{mo}$ \\
\hline Overall & 5.7 & 9.5 & 12.8 & 3.1 & 5.3 & 7.4 \\
\hline \multicolumn{7}{|l|}{ Gender } \\
\hline Female & 5.4 & 9.5 & 12.9 & 2.8 & 5.1 & 7.1 \\
\hline Male & 6.0 & 9.4 & 12.7 & 3.4 & 5.5 & 7.7 \\
\hline \multicolumn{7}{|l|}{ Age group (y) } \\
\hline $18-64$ & 1.7 & 3.1 & 4.4 & 0.9 & 1.6 & 2.3 \\
\hline $65-80$ & 7.3 & 11.6 & 17.2 & 6.8 & 10.7 & 16.1 \\
\hline$>80$ & 13.9 & 23.4 & 29.4 & 13.2 & 22.3 & 28.4 \\
\hline \multicolumn{7}{|c|}{ Comorbidity level ${ }^{\mathrm{b}}$} \\
\hline Low & 2.0 & 3.0 & 4.2 & 1.0 & 1.5 & 2.1 \\
\hline Moderate & 6.3 & 10.6 & 14.5 & 4.2 & 7.2 & 10.1 \\
\hline High & 11.7 & 20.1 & 26.5 & 10.8 & 18.6 & 24.8 \\
\hline
\end{tabular}

Notes: adjusted for gender, age as continuous variable, and comorbidity level ( 2 in each analysis); 'Three levels of comorbidity were defined based on Charlson index scores of 0 (low), I-2 (moderate), and 3 or more (high).

\section{Relative mortality}

The results from the Cox regression analysis are presented in Tables 4 and 5. The overall adjusted HR comparing males with females was 1.16 (95\% CI, 0.97-1.39). Compared with patients younger than 65 years, the adjusted HR was 2.77 (95\% CI, 2.11-3.64) for patients aged 65-80 years and 5.25 (95\% CI, 4.06-6.80) for patients older than 80 years. The impact of increasing age on the mortality HR was most evident among patients with low comorbidity. Compared with low comorbidity patients, the adjusted HR was 2.43 (95\% CI, $1.82-3.24$ ) for patients with a moderate comorbidity and 3.87 (95\% CI, 2.91-5.15) for patients with a high comorbidity. The impact of comorbidity level on the mortality HR was most evident in the youngest group of patients.

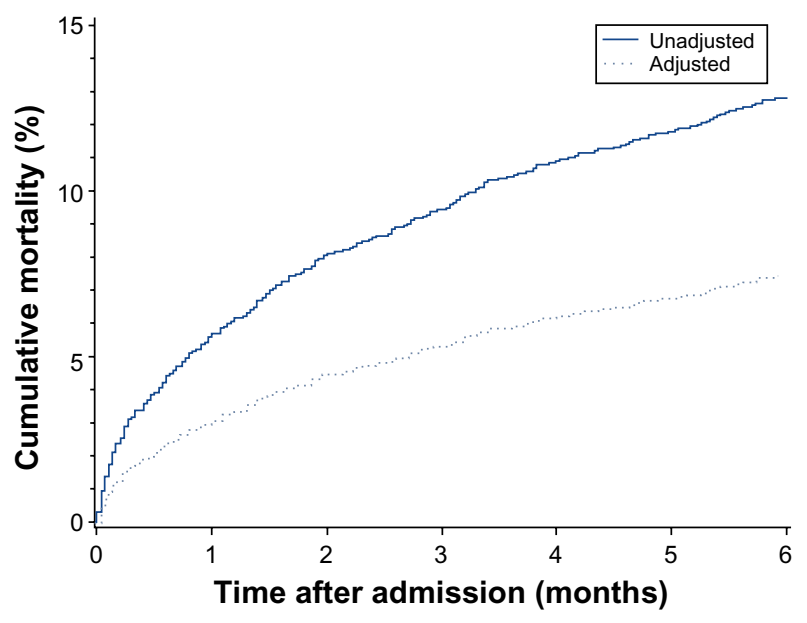

Figure 2 Mortality for all patients.

\section{Discussion}

In this population-based cohort study, age and comorbidity level were important predictors of 1-, 3-, and 6-month mortality following acute admission to the MAU at Aarhus University Hospital, Nørrebrogade. Furthermore, age and comorbidity seemed to modify the effect of each other. Thus, the prognostic effect of comorbidity level decreased with increasing age, and vice versa. Thus, a high comorbidity level increases mortality rates relatively more in young patients than old patients, which may be due to the fact that old age itself increases mortality rates substantially. Although not substantial, male gender may also be a predictor of mortality.

This feasibility study is the first to examine the 6-month mortality after acute admission to a MAU in a Scandinavian population-based setting. The design presented has not previously been described in Denmark for patients admitted to a MAU and may therefore be used in future studies on the prevalence and course of acute medical diseases and on prognostic factors for different outcomes of interest.

Comorbidity was a major prognostic factor in our study. Because the population is aging, it is expected that an increasing proportion of acutely hospitalized medical patients will present with more comorbidity in the future. ${ }^{2}$ It is therefore important to identify prognostic comorbid conditions associated with acute medical diseases to plan health-care needs, evaluate effectiveness of hospital care, and prevent posthospital death. To examine whether comorbid diseases and index conditions interact with one another to increase mortality (beyond their independent effects alone), future studies should include a comparison cohort from the general population matched on gender and age and calculate the comorbidity level for members of this comparison cohort also.

Several issues should be considered when interpreting our results. Our population-based design within a tax-supported universal health-care system with complete, independently and prospectively recorded medical history reduced the risk of referral, diagnostic, and information biases. ${ }^{16}$

The department registration procedure in the DNPR made it possible to identify hospital admissions for acute medical conditions ${ }^{17}$ as well as all in-hospital mortality. A limitation was that we were not able to include patients with acute myocardial infarction or stroke. The fact that 1 in 6 index conditions were imprecisely coded as "medical observation and evaluation for suspected diseases and conditions" does not affect the present study but suggest that some index conditions are underreported in the DNPR. 

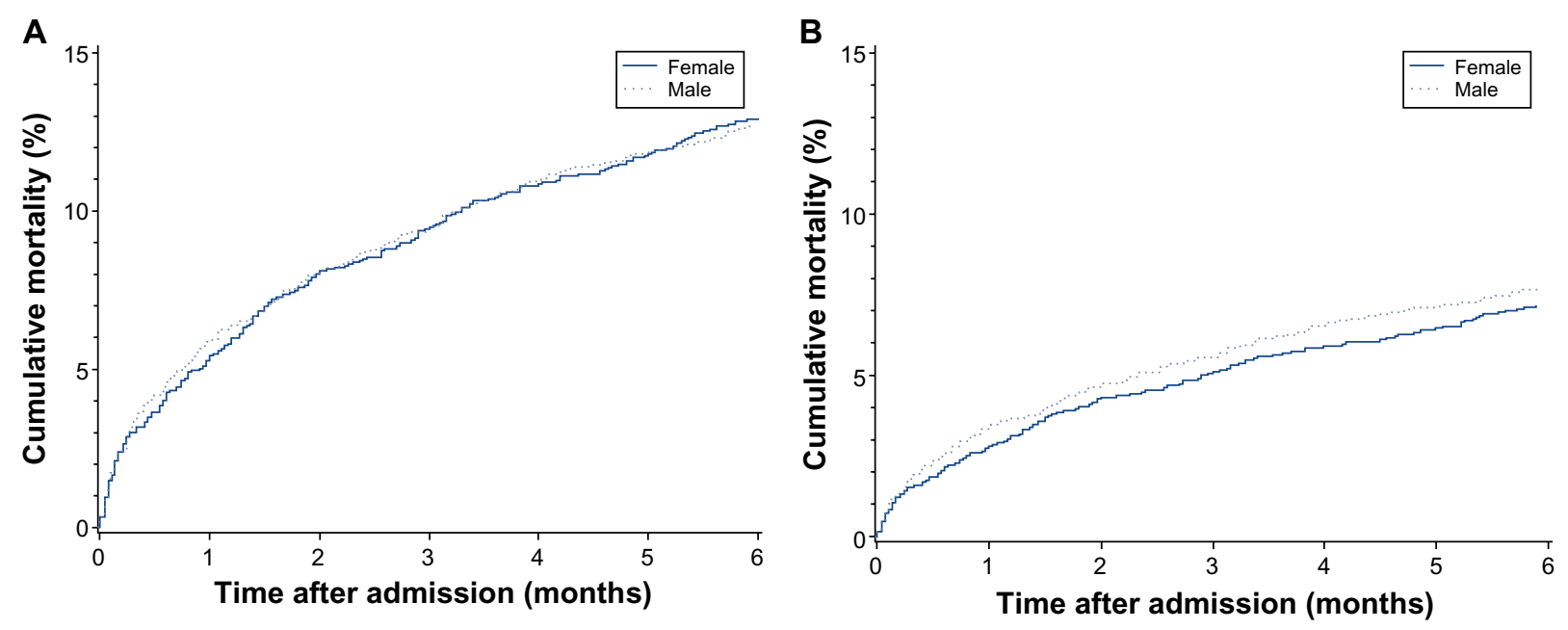

Figure 3 Mortality according to gender. A) Unadjusted; B) adjusted.
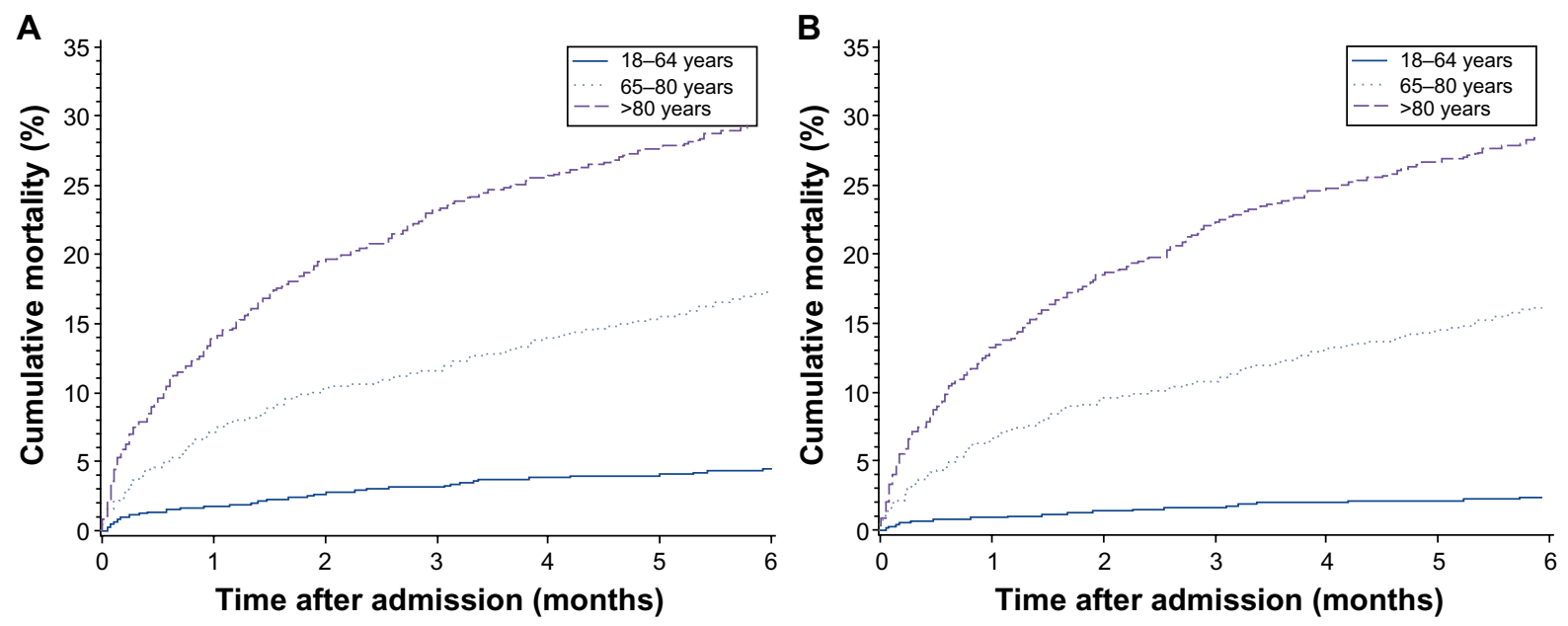

Figure 4 Mortality according to age groups. A) Unadjusted; B) adjusted.
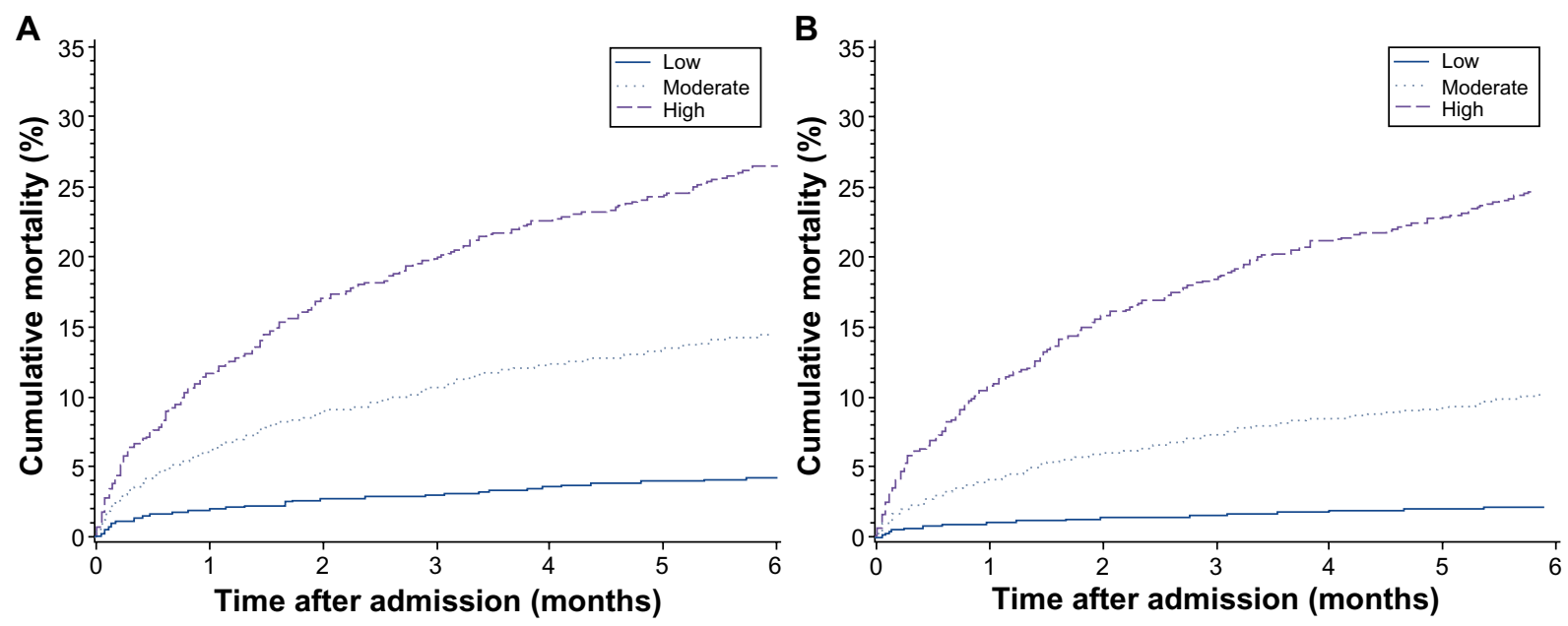

Figure 5 Mortality according to comorbidity level. A) Unadjusted; B) adjusted. 
Table 4 Mortality hazard ratios within gender, age, and comorbidity groups

\begin{tabular}{|c|c|c|}
\hline & \multicolumn{2}{|c|}{$\begin{array}{l}\text { Hazard ratios } \\
\text { ( } 95 \% \text { confidence intervals) }\end{array}$} \\
\hline & Unadjusted & Adjusted $^{a}$ \\
\hline \multicolumn{3}{|l|}{ Gender } \\
\hline Female & 1.00 (reference) & 1.00 (reference) \\
\hline Male & $0.99(0.82-1.18)$ & 1.16 (0.97-I.39) \\
\hline \multicolumn{3}{|l|}{ Age group (y) } \\
\hline 18-64 & 1.00 (reference) & 1.00 (reference) \\
\hline $65-80$ & $4.16(3.20-5.39)$ & $2.77(2.1 \mathrm{I}-3.64)$ \\
\hline$>80$ & $7.76(6.08-9.90)$ & $5.25(4.06-6.80)$ \\
\hline \multicolumn{3}{|c|}{ Comorbidity level $^{\mathrm{b}}$} \\
\hline Low & I.00 (reference) & 1.00 (reference) \\
\hline Moderate & $3.65(2.76-4.83)$ & $2.43(1.82-3.24)$ \\
\hline High & 7.15 (5.45-9.37) & $3.87(2.91-5.15)$ \\
\hline
\end{tabular}

Notes: aAdjusted for gender, age as a continuous variable, and comorbidity level (2

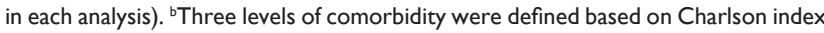
scores of 0 (low), 1-2 (moderate), and 3 or more (high).

Table 5 Mortality hazard ratios stratified on gender, age, and comorbidity groups

\begin{tabular}{|c|c|c|}
\hline & \multicolumn{2}{|c|}{$\begin{array}{l}\text { Hazard ratios } \\
\text { (95\% confidence intervals) }\end{array}$} \\
\hline & Unadjusted & Adjusted $^{a}$ \\
\hline \multicolumn{3}{|l|}{ Female patients } \\
\hline Age 65-80 & $4.74(3.20-7.03)$ & $2.93(I .95-4.4 I)$ \\
\hline Age $>80$ & $8.73(6.08-12.53)$ & $5.26(3.60-7.68)$ \\
\hline Moderate comorbidity & $4.38(2.94-6.5 \mathrm{I})$ & $2.79(I .86-4.21)$ \\
\hline High comorbidity & $8.98(6.09-13.25)$ & $4.74(3.15-7.13)$ \\
\hline \multicolumn{3}{|l|}{ Male patients } \\
\hline Age $65-80$ & $3.77(2.65-5.34)$ & $2.68(1.86-3.86)$ \\
\hline Age $>80$ & $7.56(5.38-10.63)$ & $5.35(3.74-7.65)$ \\
\hline Moderate comorbidity & $3.02(2.03-4.47)$ & $2.11(1.4 I-3.16)$ \\
\hline High comorbidity & $5.61(3.84-8.20)$ & $3.11(2.08-4.65)$ \\
\hline \multicolumn{3}{|l|}{ Patients aged $18-64$ y } \\
\hline Male & I.I8 (0.78-1.80) & $1.12(0.74-1.71)$ \\
\hline Moderate comorbidity & $2.12(1.22-3.67)$ & $2.10(1.21-3.65)$ \\
\hline High comorbidity & $4.65(2.68-8.09)$ & $4.62(2.66-8.03)$ \\
\hline \multicolumn{3}{|l|}{ Patients aged $65-80$ y } \\
\hline Male & I.I6 (0.84-1.59) & $1.09(0.79-1.50)$ \\
\hline Moderate comorbidity & $1.59(0.95-2.68)$ & $1.58(0.94-2.66)$ \\
\hline High comorbidity & $2.79(1.7 I-4.56)$ & $2.76(1.69-4.52)$ \\
\hline \multicolumn{3}{|l|}{ Patients aged $\geq 80 \mathrm{y}$} \\
\hline Male & $1.27(0.98-1.66)$ & $1.24(0.95-1.61)$ \\
\hline Moderate comorbidity & $2.19(1.42-3.37)$ & $2.20(1.43-3.39)$ \\
\hline High comorbidity & 2.89 (1.88-4.43) & $2.85(1.86-4.37)$ \\
\hline \multicolumn{3}{|c|}{ Patients with low comorbidity ${ }^{b}$} \\
\hline Male & $1.35(0.84-2.18)$ & $1.70(1.05-2.74)$ \\
\hline Age $65-80$ & $5.38(2.93-9.85)$ & $5.55(3.03-10.18)$ \\
\hline Age $>80$ & $9.05(5.13-15.96)$ & $9.83(5.54-17.44)$ \\
\hline \multicolumn{3}{|c|}{ Patients with moderate comorbidity ${ }^{\mathrm{b}}$} \\
\hline Male & $0.94(0.70-1.26)$ & $1.24(0.92-1.68)$ \\
\hline Age $65-80$ & $2.8 \mathrm{I}(\mathrm{I} .8 \mathrm{I}-4.37)$ & $2.83(1.82-4.40)$ \\
\hline Age $>80$ & $6.22(4.17-9.28)$ & $6.54(4.36-9.8 I)$ \\
\hline \multicolumn{3}{|c|}{ Patients with high comorbidity ${ }^{b}$} \\
\hline Male & $0.85(0.66-1.10)$ & $0.98(0.75-1.27)$ \\
\hline Age $65-80$ & $1.70(1.15-2.5 \mathrm{I})$ & $1.69(1 . \mid 4-2.5 I)$ \\
\hline Age $>80$ & $2.82(1.94-4.1 \mathrm{I})$ & $2.8 I(I .92-4 . I I)$ \\
\hline
\end{tabular}

Notes: The reference groups (not shown) were female patients, patients aged 18 64 years, and patients with low comorbidity.

aThe adjustments differed between strata and included only the nonstratifying variable (either gender, age as a continuous variable, or comorbidity level). As an exception for age strata, additional adjustment for age as a continuous variable was made; ${ }^{\mathrm{b}}$ Three levels of comorbidity were defined based on Charlson index scores of 0 (low), I-2 (moderate), and 3 or more (high).
It is possible that confounding by unmeasured variables, such as former or current use of tobacco, alcohol, and medications, and biochemical markers, influenced our results. Future studies should, if possible, include such variables ${ }^{18,19}$ and furthermore differentiate between index conditions because risk factors, prognostic factors, and survival probabilities vary among these conditions. Comparing mortality following acute medical conditions for different time periods may also add evidence on the effectiveness of newer treatment regimens. Moreover, comparing whether short-term or long-term mortality depends on the admission time during the day and week may challenge the internal organization of health-care systems. Other important outcome measures include length of stay, hospital acquired infections, venous thromboembolism, readmission rates, cause-specific mortality, and in-hospital mortality.

In conclusion, age and comorbidity were important predictors of mortality after acute medical admission.

\section{Disclosure}

The authors report no conflicts of interest in this work.

\section{References}

1. Gavrilov LA, Heuveline P. Aging of population. In: Demeny P, McNicoll G, editors. The Encyclopedia of Population. New York: Macmillan Reference USA; 2003.

2. Wolff JL, Starfield B, Anderson G. Prevalence, expenditures, and complications of multiple chronic conditions in the elderly. Arch Intern Med. 2002;162(20):2269-2276.

3. Statistics Denmark. www.dst.dk

4. Hoffman C, Rice D, Sung HY. Persons with chronic conditions. Their prevalence and costs. JAMA. 1996;276(18):1473-1479.

5. Vaartjes I, de Borst GJ, Reitsma JB, et al. Long-term survival after initial hospital admission for peripheral arterial disease in the lower extremities. BMC Cardiovasc Disord. 2009;9:43.

6. Frank L. Epidemiology. When an entire country is a cohort. Science. 2000;287(5462):2398-2399.

7. Andersen TF, Madsen M, Jorgensen J, Mellemkjaer L, Olsen JH. The Danish National Hospital Register. A valuable source of data for modern health sciences. Dan Med Bull. 1999;46(3):263-268.

8. Pedersen CB, Gøtzsche H, Møller JO, Mortensen PB. The Danish Civil Registration System. A cohort of eight million persons. Dan Med Bull. 2006;53(4):441-449.

9. Sørensen HT, Christensen S, Mehnert F, et al. Use of bisphosphonates among women and risk of atrial fibrillation and flutter: population based case-control study. BMJ. 2008;336(7648):813-816.

10. Charlson ME, Pompei P, Ales K1, MacKenzie CR. A new method of classifying prognostic comorbidity in longitudinal studies: development and validation. J Chronic Dis. 1987;40(5):373-383.

11. de Groot V, Beckerman H, Lankhorst GJ, Bouter LM. How to measure comorbidity. A critical review of available methods. J Clin Epidemiol. 2003;56(3):221-229.

12. Deyo RA, Cherkin DC, Ciol MA. Adapting a clinical comorbidity index for use with ICD-9-CM administrative databases. J Clin Epidemiol. 1992;45(6):613-619.

13. D'Hoore W, Bouckaert A, Tilquin C. Practical considerations on the use of the Charlson comorbidity index with administrative data bases. J Clin Epidemiol. 1996;49(12):1429-1433. 
14. Taha AS, McCloskey C, Prasad R, Bezlyak V. Famotidine for the prevention of peptic ulcers and oesophagitis in patients taking lowdose aspirin (FAMOUS): a phase III, randomised, double-blind, placebo-controlled trial. Lancet. 2009;374(9684):119-125.

15. Nieto FJ, Coresh J. Adjusting survival curves for confounders: a review and a new method. Am J Epidemiol. 1996;143(10):1059-1068.

16. Sørensen HT. Regional administrative health registers as a resource in clinical epidemiology. A study of options, strengths, limitations and data quality provided with examples of use. Int J Risk Safety Med. 1997;10:1-22.
17. Weiss NS. Clinical epidemiology. In: Rothman KJ, Greenland S, Lash TL, editors. Modern Epidemiology. 3rd ed. Philadelphia, PA: Lippincott Williams and Wilkins; 2008:642-646.

18. Christiansen JU, Maruard CD, Nielsen HC. LABKA. A real-time computer system for the clinical laboratory. Scand J Clin Lab Invest Suppl. 1989;194:57-61.

19. Gaist D, Andersen M, Aarup Al, Hallas J, Gram LF. Use of sumatriptan in Denmark in 1994-5: an epidemiological analysis of nationwide prescription data. Br J Clin Pharmacol. 1997;43(4):429-433. 


\section{Appendix \\ ICD codes for Charlson comorbidity index}

Myocardial infarction: $I C D-8$ : 410; ICD-10: I21, I22, I23.

Congestive heart failure: $I C D-8: 427.09,427.10,427.11$, 427.19, 428.99, 782.49; ICD-10: I50, I11.0, I13.0, I13.2.

Peripheral vascular disease: $I C D-8: 440,441,442,443,444$, 445; ICD-10: I70, I71, I72, I73, I74, I77.

Cerebrovascular disease: ICD-8: 430-438; ICD-10: I60-I69, G45, G46.

Dementia: ICD-8: 290.09-290.19, 293.09; ICD-10: F00F03, F05.1, G30.

Chronic pulmonary disease: $I C D-8$ : 490-493, 515-518; ICD-10: J40-J47, J60-J67, J68.4, J70.1, J70.3, J84.1, J92.0, J96.1, J98.2, J98.3.

Connective tissue disease: ICD-8: 712, 716, 734, 446, 135.99; ICD-10: M05, M06, M08, M09, M30, M31, M32, M33, M34, M35, M36, D86.

Ulcer disease: ICD-8: 530.91, 530.98, 531-534; ICD-10: K22.1, K25-K28.

Mild liver disease: $I C D-8: 571,573.01,573.04 ; I C D-10$ : B18, K70.0-K70.3, K70.9, K71, K73, K74, K76.0.

Clinical Epidemiology

\section{Publish your work in this journal}

Clinical Epidemiology is an international, peer-reviewed, open access journal focusing on disease and drug epidemiology, identification of risk factors and screening procedures to develop optimal preventative initiatives and programs. Specific topics include: diagnosis, prognosis, treatment, screening, prevention, risk factor modification, systematic
Diabetes mellitus: $I C D-8: 249.00,249.06,249.07,249.09$, 250.00, 250.06, 250.07, 250.09; ICD-10: E10.0, E10.1, E10.9, E11.0, E11.1, E11.9.

Hemiplegia: ICD-8: 344; ICD-10: G81, G82.

Moderate to severe renal disease: $I C D-8: 403,404,580-583$, 584, 590.09, 593.19, 753.10-753.19, 792; ICD-10: I12, I13, N00-N05, N07, N11, N14, N17-N19, Q61.

Diabetes with end-organ damage: ICD-8: 249.01-249.05, 249.08, 250.01-250.05, 250.08; ICD-10: E10.2-E10.8, E11.2-E11.8.

Any tumor: ICD-8: 140-194; ICD-10: C00-C75.

Leukemia: ICD-8: 204-207; ICD-10: C91-C95.

Lymphoma: ICD-8: 200-203, 275.59; ICD-10: C81-C85, C88, C90, C96.

Moderate to severe liver disease: $I C D-8: 070.00,070.02$, 070.04, 070.06, 070.08, 573.00, 456.00-456.09; ICD-10: B15.0, B16.0, B16.2, B19.0, K70.4, K72, K76.6, I85;

Metastatic solid tumor: ICD-8: 195-198, 199; ICD-10: C76-C80.

AIDS: ICD-8: 079.83; ICD-10: B21-B24.

\section{Dovepress}

reviews, risk \& safety of medical interventions, epidemiology \& biostatical methods, evaluation of guidelines, translational medicine, health policies \& economic evaluations. The manuscript management system is completely online and includes a very quick and fair peer-review system, which is all easy to use. 